\title{
Effect of Microalloying with Silicon on High Temperature Oxidation Resistance of Novel Refractory High-Entropy Alloy Ta-Mo-Cr-Ti-Al
}

Franz Mueller ${ }^{\mathrm{a}}$, Bronislava Gorr ${ }^{\mathrm{a}}$, Hans-Juergen Christ $^{\mathrm{a}}$, Hans Chen ${ }^{\mathrm{b}}$, Alexander Kauffmann $^{\mathrm{b}}$, Martin Heilmaier ${ }^{\mathrm{b}}$

${ }^{a}$ Institut für Werkstofftechnik, Universität Siegen, Siegen, GERMANY

${ }^{b}$ Institut für Angewandte Materialien, Karlsruher Institut für Technologie

(KIT),Karlsruhe, GERMANY

F.Mueller

Institut für Werkstofftechnik, Universität Siegen, Paul-Bonatz-Strasse 9-11, 57068 Siegen (GERMANY)

Email: franz.mueller@uni-siegen.de 


\title{
Effect of Microalloying with Silicon on High Temperature Oxidation Resistance of Novel Refractory High-Entropy Alloy Ta-Mo-Cr-Ti-Al
}

\author{
The effect of 1 at.\% Si addition to the refractory high-entropy alloy (HEA) Ta- \\ Mo-Cr-Ti-Al on the high temperature oxidation resistance in air between $900{ }^{\circ} \mathrm{C}$ \\ and $1100{ }^{\circ} \mathrm{C}$ was studied. Due to the formation of protective chromia-rich and \\ alumina scales, the thermogravimetric curves for Ta-Mo-Cr-Ti-Al and Ta-Mo- \\ $\mathrm{Cr}-\mathrm{Ti}-\mathrm{Al}-1 \mathrm{Si}$ showed small mass changes and low oxidation rates which are on \\ the level of chromia-forming alloys. The oxide scales formed on both alloys at all \\ temperatures are complex and consist of outermost $\mathrm{TiO}_{2}$, intermediate $\mathrm{Al}_{2} \mathrm{O}_{3}$, and \\ (Cr,Ta,Ti)-rich oxide at the interface oxide/substrate. The Si addition had a \\ slightly detrimental effect on the oxidation resistance at all temperatures \\ primarily as a result of increased internal corrosion attack observed in the Si- \\ containing HEA. Large Laves phase particles distinctly found in the $\mathrm{Si}$ - \\ containing alloy were identified to be responsible for the more rapid internal \\ corrosion.
}

Keywords: High-entropy alloys; silicon effect; refractory metals; Laves phase; internal corrosion; high-temperature corrosion

\section{Introduction}

High-Entropy Alloys (HEAs) represent a novel class of multicomponent alloys which have drawn increasing attention among the material scientists worldwide because of a new attractive and simple concept of alloy design giving rise to unique properties of some HEAs [1-3]. In general, HEAs consist of at least 5 elements in equal or near-equal concentrations. From a thermodynamic point of view, HEAs should exhibit much larger mixing entropies than conventional alloys which may result in suppression of the formation of ordered intermetallic compounds, hence, promoting the formation of single-phase solid solutions with simple crystal structures [1]. However, experimental studies on numerous HEAs revealed that most of them do not show a single phase microstructure, rather intermetallic ordered phases such as like Laves, Sigma or higher 
ordered B2 phases form in addition to the disordered solid solutions $[4,5]$. In this case, according to Senkov [5], the term multi-principal element alloys (MPEA) may be more appropriate. Such two-phase alloys often show more interesting properties compared to those of the single-phase HEAs. For example, many refractory HEAs, which have been designed for high temperature structural applications and indeed show remarkable high temperature strength, also exhibit a multi-phase microstructure. Senkov et al. reported on two refractory HEAs $\mathrm{Nb}-\mathrm{Cr}-\mathrm{Ti}-\mathrm{Zr}$ and $\mathrm{Nb}-\mathrm{V}-\mathrm{Cr}-\mathrm{Ti}-\mathrm{Zr}$ which consist of a disordered body-centered cubic (bcc) and an ordered C15 Laves phase. These alloys offer attractive properties as they exhibit high hardness due to the formation of the Laves phase accompanied by a favourably low density [6]. Another alloy system on basis of Al-Mo$\mathrm{Nb}-\mathrm{Ta}-\mathrm{Ti}-\mathrm{Zr}$ was found to form either a single-phase disordered cubic bcc crystal structure or a two-phase microstructure including the coherent ordered B2 phase [7]. Interestingly, the alloy with the coherent two-phase bcc/B2 microstructure $\mathrm{Al}-\mathrm{Mo}_{0.5^{-}}$ $\mathrm{Nb}-\mathrm{Ta}_{0.5}-\mathrm{Ti}-\mathrm{Zr}$ exhibits a very high yield strength which is even superior to that of $\mathrm{Ni}$ based superalloys in the temperature range from $20^{\circ} \mathrm{C}$ to $1200^{\circ} \mathrm{C}$ [8]. Our own studies on the equiatomic alloy $\mathrm{Nb}-\mathrm{Mo}-\mathrm{Cr}-\mathrm{Ti}-\mathrm{Al}$ showed that the alloy microstructure after the heat treatment at $1300^{\circ} \mathrm{C}$ consists of a disordered bcc-matrix and a small amount $(<0.5$ vol.\%) of $\mathrm{Cr}_{2} \mathrm{Nb}$ Laves phase (C14, hexagonal) located predominately at the grain boundaries. Compression tests conducted at various temperatures showed relatively high yield strength up to $800{ }^{\circ} \mathrm{C}$ and an increasing ductility with increasing test temperature [9]. At temperatures up to approximately $400^{\circ} \mathrm{C}$, the alloy, however, exhibits brittle behaviour. It was, though, found by hardness indentations in the grain interior that the bcc-matrix is plastically deformable and the alloy brittleness at low temperatures can be attributed to the presence of the Laves phase.

Although many refractory HEAs show outstanding mechanical properties [8], they 
usually possess moderate high temperature corrosion resistance due to the formation of thick, complex, non-protective or volatile oxides. Senkov et al. investigated the oxidation behaviour of the refractory $\mathrm{HEA} \mathrm{Nb}-\mathrm{Cr}-\mathrm{Mo}_{0.5}-\mathrm{Ta}_{0.5}-\mathrm{Ti}-\mathrm{Zr}$ at $1000^{\circ} \mathrm{C}$ in air and found moderate oxidation resistance with nearly parabolic oxidation rates. The evaporation of molybdenum oxide leads to the formation of pores in one of the two bcc matrix phases. Further, cracks formed during oxidation in the regions of the Laves phase were observed [10]. By contrast, our own studies on the high temperature oxidation of $\mathrm{Nb}-\mathrm{Mo}-\mathrm{Cr}-\mathrm{Ti}-\mathrm{Al}$ between $900^{\circ} \mathrm{C}-1100^{\circ} \mathrm{C}$ in air showed linear oxidation rates and the formation of predominantly thick, non-protective oxide scales consisting of a mixed rutile solid solution phase [11]. In the very recent study, the beneficial effect of 1 at.\% silicon addition to the refractory HEA Nb-Mo-Cr-Ti-Al on the oxidation resistance at $900^{\circ} \mathrm{C}-1000{ }^{\circ} \mathrm{C}$ was found [11].

Minor additions of silicon, which do not lead to the formation of brittle silicides, are, in general, beneficial in terms of the formation of protective oxide layers [12-15]. The most accepted theories on the Si effect on the oxidation behavior of chromia forming alloys are - depending on the alloy system - (i) the formation of a protective silica scale on the phase boundary substrate/oxide $[16,17]$ and (ii) the promotion of the development of a protective chromia layer, triggered by $\mathrm{SiO}_{2}$ nucleation sites [18-20]. Bhowmik et al. investigated the effect of silicon additions to $\mathrm{Cr}-\mathrm{Cr}_{2} \mathrm{Ta}$-based alloys, which consisted of a eutectic of $\mathrm{Cr}$-based solid solution and the $\mathrm{Cr}_{2} \mathrm{Ta}$ Laves phases with hexagonal C14 and C36 polymorph [12]. There, it was found that silicon additions of up to 7 at. \% clearly improve the oxidation characteristics at $1000{ }^{\circ} \mathrm{C}$ and $1100{ }^{\circ} \mathrm{C}$. Further, the silicon addition proofed to be beneficial for the fracture toughness by reducing the extent of internal nitridation [12].

In the present study, the oxidation behaviour of two refractory HEAs Ta-Mo-Cr-Ti-Al 
and Ta-Mo-Cr-Ti-Al-1Si at temperatures between $900^{\circ} \mathrm{C}-1100^{\circ} \mathrm{C}$ in air is comparatively investigated in order to understand the impact of a minor Si addition on the oxidation resistance. Specifically, a mechanism-based consideration will be carried out comparing the results obtained with the positive effect of Si observed on the oxidation behaviour in the equiatomic alloy Nb-Mo-Cr-Ti-Al [11].

\section{Experimental Procedures}

The alloys were cast from elemental bulk material by arc-melting (arc-melter AM 0.5 by Edmund Bühler $\mathrm{GmbH}$ ) in $~ 0.6 \mathrm{~atm}$. of argon. The purities of the used elemental bulk materials Ta and Mo were 99.9\%, while $\mathrm{Cr}$, Ti, Al, Si had purities of $99 \%, 99.8 \%$, $99.9 \%$ and $99.9999 \%$, respectively. The prepared buttons were flipped over and remelted at least five times in a water-chilled copper mold to facilitate alloy homogenization. The alloys were subsequently heat-treated at $1400{ }^{\circ} \mathrm{C}$ for $20 \mathrm{~h}$ in inert atmosphere. The ingots were then cut by electrical discharge machining (EDM) to dimensions of approximately $5 \mathrm{~mm} \times 5 \mathrm{~mm} \times 2 \mathrm{~mm}$, polished up to 1200 grit and ultrasonically cleaned in ethanol directly before high-temperature exposure. The oxidation tests were carried out in a Rubotherm thermogravimetric system under isothermal conditions in laboratory air. To analyse the oxide morphology, a Focused Ion Beam - Scanning Electron Microscope (FIB-SEM) DualBeam system of type FEI Helios Nanolab 600 in combination with backscatter electron (BSE) imaging and energy dispersive X-ray spectroscopy (EDX) as well as electron backscatter diffraction (EBSD) was used. The composition of the oxide scales was analysed by X-ray diffraction (XRD) on oxidized samples. The XRD measurements were carried out using a X'Pert Pro MPD diffractometer operating in Bragg-Brentano geometry as described in Ref. [11]. 


\section{Results}

The overall compositions of the refractory high-entropy alloys are $20 \mathrm{Ta}-20 \mathrm{Mo}-20 \mathrm{Cr}$ 20Ti-20Al and 19.8Ta-19.8Mo-19.8Cr-19.8Ti-19.8Al-1Si (in at. \%). After arc melting and homogenization at $1400^{\circ} \mathrm{C}$ for 20 hours both HEAs still show a multi-phase microstructure, i.e. an alloy matrix and Laves phases rich in $\mathrm{Cr}$, $\mathrm{Ta}$ and $\mathrm{Al}$ as can be seen in Fig. 1 a) and b). Additional analyses using XRD (see. Fig. 2), EBSD and TEM (not shown here) revealed three modifications of Laves phase, i.e. hexagonal C14, cubic $\mathrm{C} 15$ and hexagonal C36, distributed in the matrix which consists of a bcc/B2 microstructure. While the relatively small particles of the Laves phase form preferably at the grain boundaries in the Si-free alloy, the particles of the Laves phase in the Sicontaining HEA are significantly bigger and homogeneously distributed in the alloy matrix.
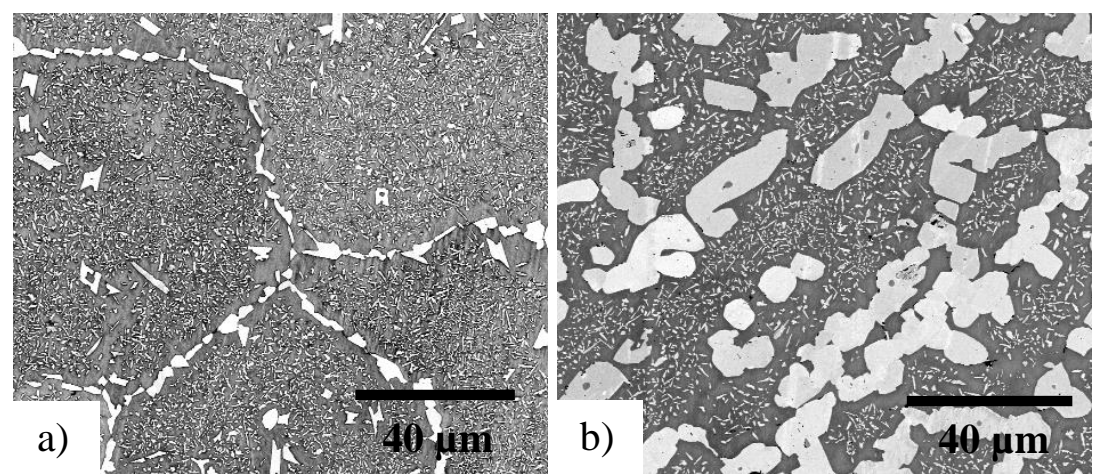

Figure 1. Backscattered electron micrographs of the substrate of a) Ta-Mo-Cr-Ti-Al and b) Ta-Mo-Cr-Ti-Al-1Si after heat treatment at $1400^{\circ} \mathrm{C}$ for $20 \mathrm{~h}$. 


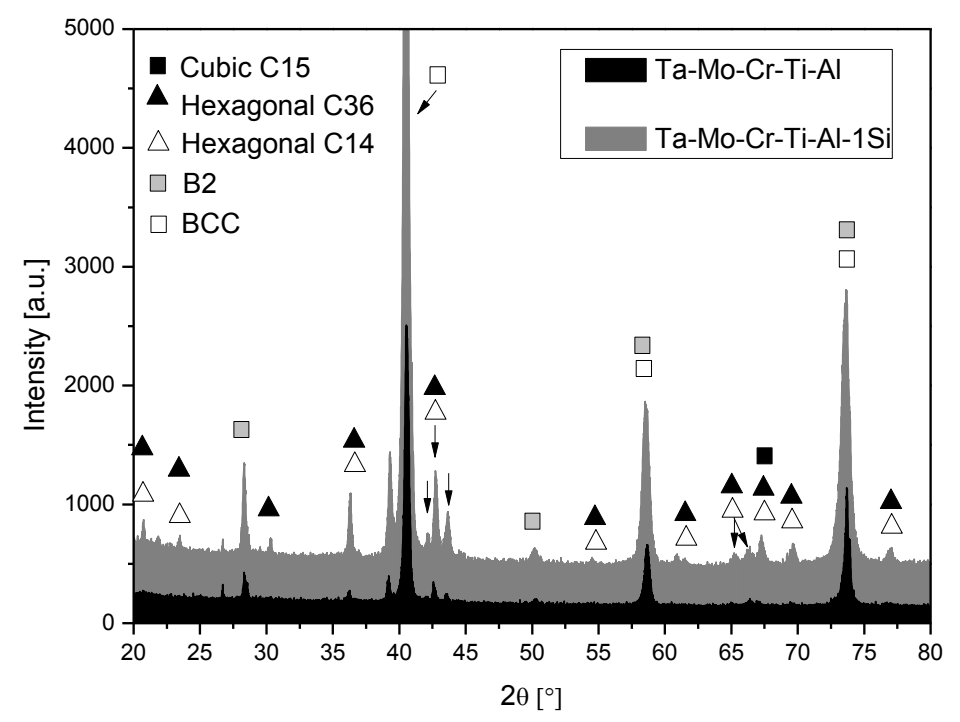

Figure 2. Results of the XRD analyses of alloys Ta-Mo-Cr-Ti-Al and Ta-Mo-Cr-Ti-Al$1 \mathrm{Si}$ after heat treatment at $1400^{\circ} \mathrm{C}$ for $20 \mathrm{~h}$.

The oxidation kinetics of the alloys Ta-Mo-Cr-Ti-Al and Ta-Mo-Cr-Ti-Al-1Si at $900{ }^{\circ} \mathrm{C}, 1000^{\circ} \mathrm{C}$ and $1100{ }^{\circ} \mathrm{C}$ in air is shown in Fig. 3a), b) and c) in double-linear representation. In order to determine whether the thermogravimetric curves obey a linear or a parabolic rate law, the square of the mass change versus time is plotted in Fig. 3 d), e) and f). The oxidation curves between $900^{\circ} \mathrm{C}-1000^{\circ} \mathrm{C}$ obviously obey the parabolic rate law after a short period of transient oxidation indicating that the growth of the oxide scale proceeds through solid-state diffusion. At $1100^{\circ} \mathrm{C}$, parabolic oxidation behaviour was only observed for Ta-Mo-Cr-Ti-Al whereas the Si-containing alloy exhibits increasing oxidation rates after $30 \mathrm{~h}$ of exposure. Although both alloys show generally relatively small mass changes and low oxidation rates at all temperatures, Ta-Mo-Cr-Ti-Al-1Si obviously possesses a lower oxidation resistance than the alloy Ta-Mo-Cr-Ti-Al. 


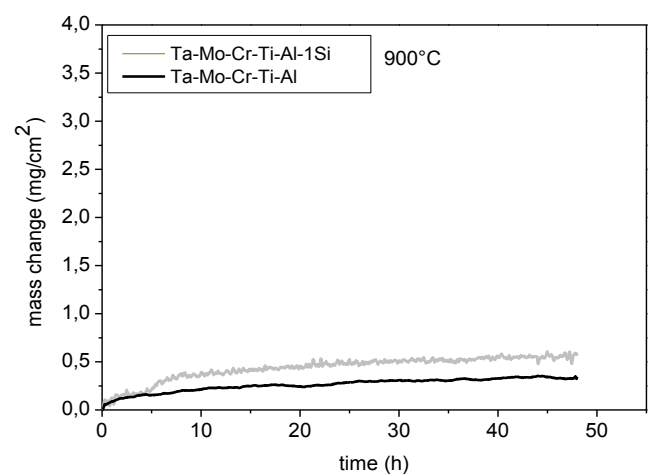

a)

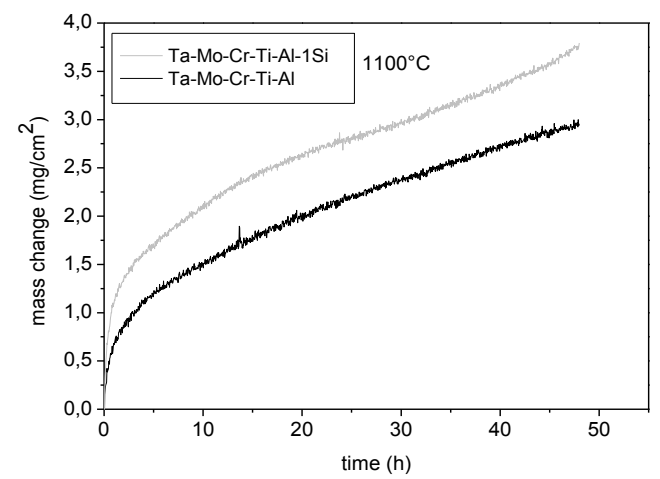

c)

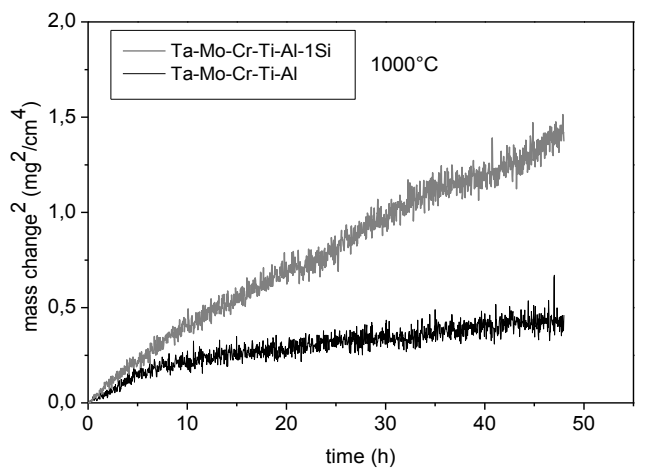

e)

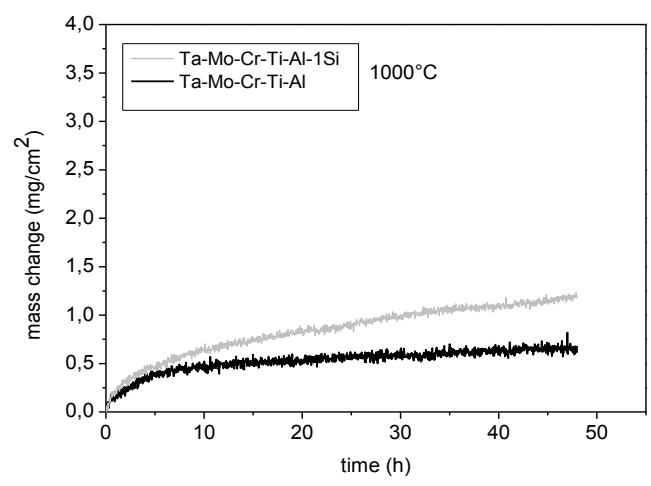

b)

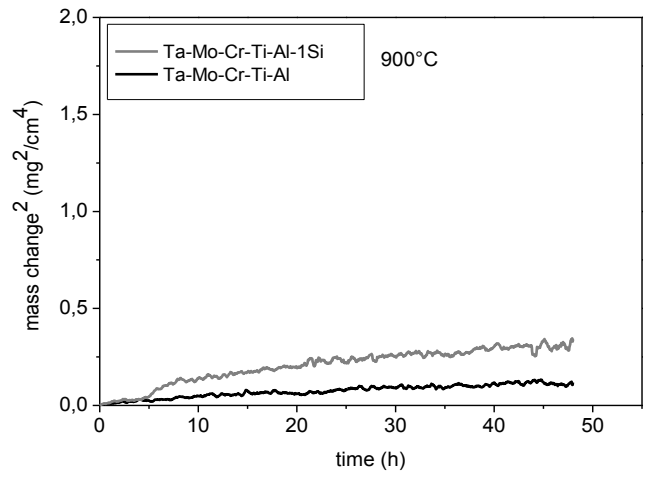

d)

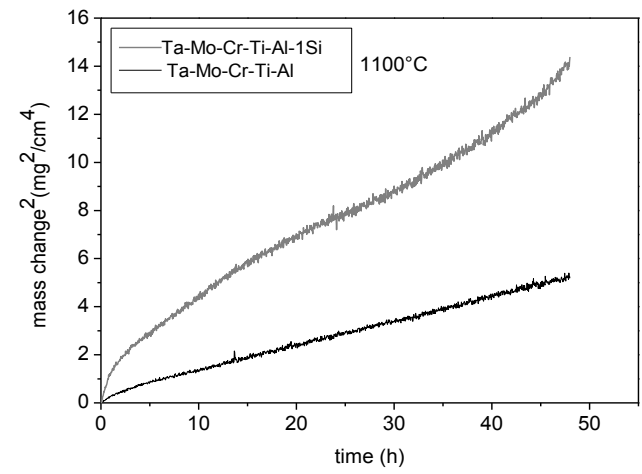

f)

Figure 3. Thermogravimetric curves of Ta -Mo-Cr-Ti-Al with and without 1 at.\% $\mathrm{Si}$ addition conducted during exposure in air at a) $900{ }^{\circ} \mathrm{C}$, b) $1000{ }^{\circ} \mathrm{C}$, c) $1100{ }^{\circ} \mathrm{C}$; corresponding plots of the square of mass change versus oxidation time at d) $900{ }^{\circ} \mathrm{C}, \mathrm{e}$ ) $1000{ }^{\circ} \mathrm{C}$ and f) $1100{ }^{\circ} \mathrm{C}$. 
Microstructural SEM examination supplemented by EDX analyses of the oxidized samples after $48 \mathrm{~h}$ of exposure at $900^{\circ} \mathrm{C}$ and $1000^{\circ} \mathrm{C}$ shows for both alloys the formation of rather similar oxide scales. Thus, the BSE micrographs of both alloys after $48 \mathrm{~h}$ of exposure at $1000^{\circ} \mathrm{C}$ are exemplarily displayed in Fig.4 to illustrate the general oxide scale morphologies that are also typical of oxides layers formed at $900^{\circ} \mathrm{C}$. Figure 4 shows that both alloys form alumina layers underneath coarse Ti oxides. Below the alumina scale, a mixture of $\mathrm{Cr}$-, Ti- and Ta-rich oxides was detected for both alloys. XRD measurements suggest the formation of $\mathrm{TiO}_{2}, \mathrm{Cr}_{2} \mathrm{O}_{3}, \mathrm{Al}_{2} \mathrm{O}_{3}$ and $\mathrm{CrTaO}_{4}$ in the oxide scale after $48 \mathrm{~h}$ of air exposure at $1000{ }^{\circ} \mathrm{C}$ for both alloys (see Fig. 5).

To determine the average thicknesses of the oxide scales formed on both alloys after $48 \mathrm{~h}$ of exposure at $900^{\circ} \mathrm{C}, 1000^{\circ} \mathrm{C}$ and $1100^{\circ} \mathrm{C}$, several cross-section micrographs were used in each of which 20 individual measurements were carried out (see Table 1). In general, the oxide scale thicknesses increase with increasing temperatures, which corresponds to the thermogravimetric results. It was also found that the oxide scales of Ta-Mo-Cr-Ti-Al are generally more homogeneous with very little thickness variation, whereas Ta-Mo-Cr-Ti-Al-1Si formed both thick and thin oxide scales. Especially at $1100^{\circ} \mathrm{C}$, Ta-Mo-Cr-Ti-Al-1Si displayed strong thickness variations depending on the location of measurement. 
Table 1. Thicknesses of oxide scales formed on Ta-Mo-Cr-Ti-Al and Ta-Mo-Cr-Ti-Al$1 \mathrm{Si}$ after $48 \mathrm{~h}$ of exposure at $900^{\circ} \mathrm{C}, 1000^{\circ} \mathrm{C}$ and $1100^{\circ} \mathrm{C}$ in air.

\begin{tabular}{|c|c|c|c|}
\hline & \multicolumn{3}{|c|}{ Oxide scale thicknesses after $48 \mathrm{~h}$ of exposure $(\mu \mathrm{m})$} \\
\hline Alloy & $900^{\circ} \mathrm{C}$ & $1000^{\circ} \mathrm{C}$ & $1100^{\circ} \mathrm{C}$ \\
\hline Ta-Mo-Cr-Ti-Al & $1.2-1.3$ & 4.9-5.0 & 7.9-9.3 \\
\hline Ta-Mo-Cr-Ti-Al-1Si & $1.3-1.9$ & $3.7-5.6$ & $9.2-16.3$ \\
\hline
\end{tabular}

Underneath the oxide scales, a pronounced zone of internal corrosion in the matrix is found in both alloys at all temperatures. Appreciably oxidized phase boundaries between the Mo/Ta-rich bcc solid-solution matrix and the Laves phase (see Fig. 4b) were observed in the alloy Ta-Mo-Cr-Ti-Al-1Si, in particular in the vicinity of the large Laves phase particles, see Fig. $1 b$.
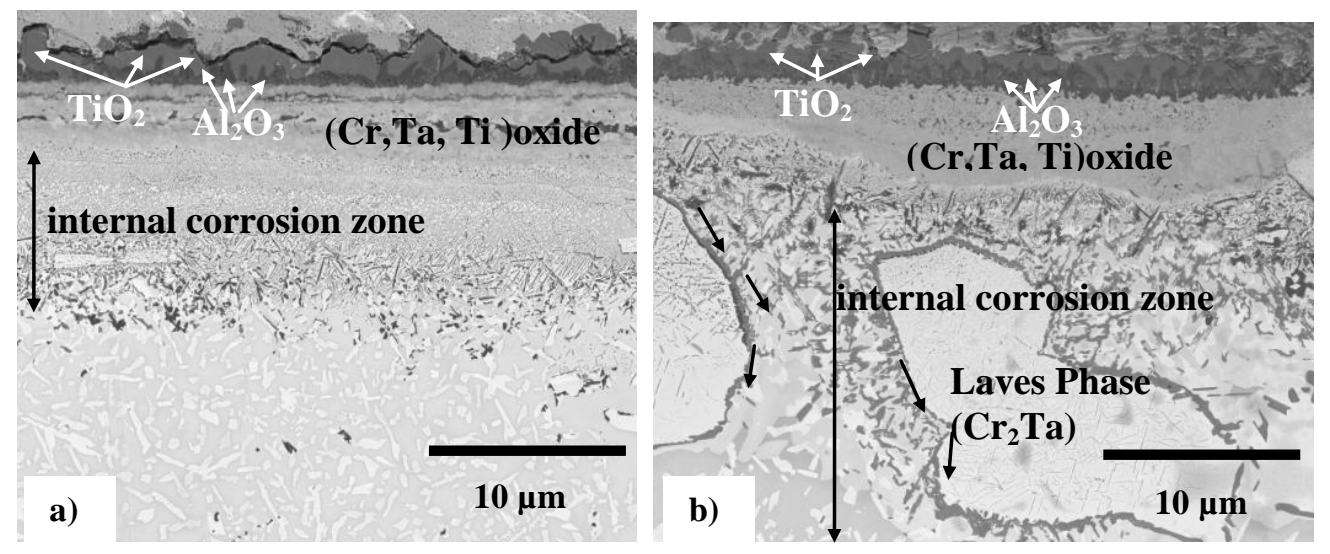

Figure 4. BSE cross-section images of oxidized $\left(48 \mathrm{~h}, 1000{ }^{\circ} \mathrm{C}\right.$, air) samples of (a) TaMo-Cr-Ti-Al, (b) Ta-Mo-Cr-Ti-Al-1Si. Oxidized phase boundaries between matrix and the Laves phase grains are marked with dark arrows.

The oxide scales formed on alloys studied at $1100^{\circ} \mathrm{C}$ are, in fact, very similar to those formed at $1000^{\circ} \mathrm{C}$, however, they revealed some particular features. Figure 6 shows micrographs of Ta-Mo-Cr-Ti-Al and Ta-Mo-Cr-Ti-Al-1Si after $48 \mathrm{~h}$ of exposure to air 
at $1100^{\circ} \mathrm{C}$. Obviously, the oxide scales are locally more buckled and, interestingly, this is even more pronounced in case of the alloy Ta-Mo-Cr-Ti-Al-1Si (see Fig. 6 b)). In addition, for Ta-Mo-Cr-Ti-Al-1Si one severely oxidized sample edge rich in Ta and partially in Cr was found (see Fig. 7).

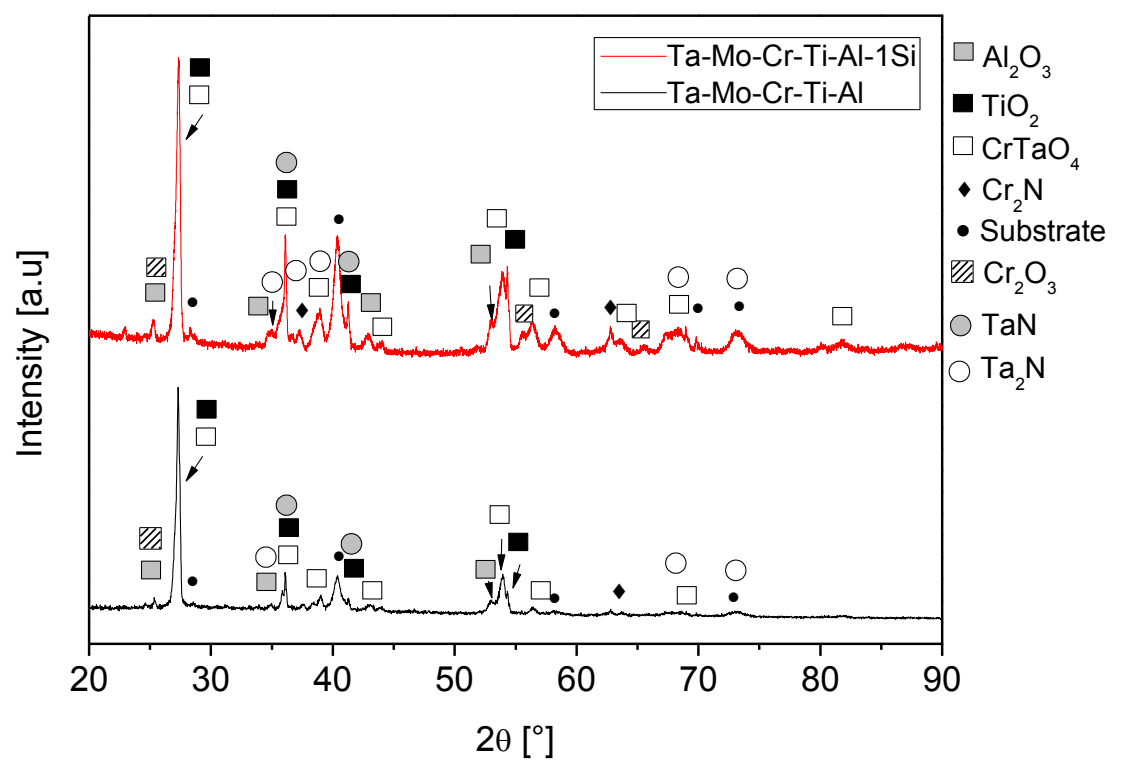

Figure 5. Results of the XRD analyses carried out on alloys Ta-Mo-Cr-Ti-Al and TaMo-Cr-Ti-Al-1Si after $48 \mathrm{~h}$ of exposure in air at $1000{ }^{\circ} \mathrm{C}$.

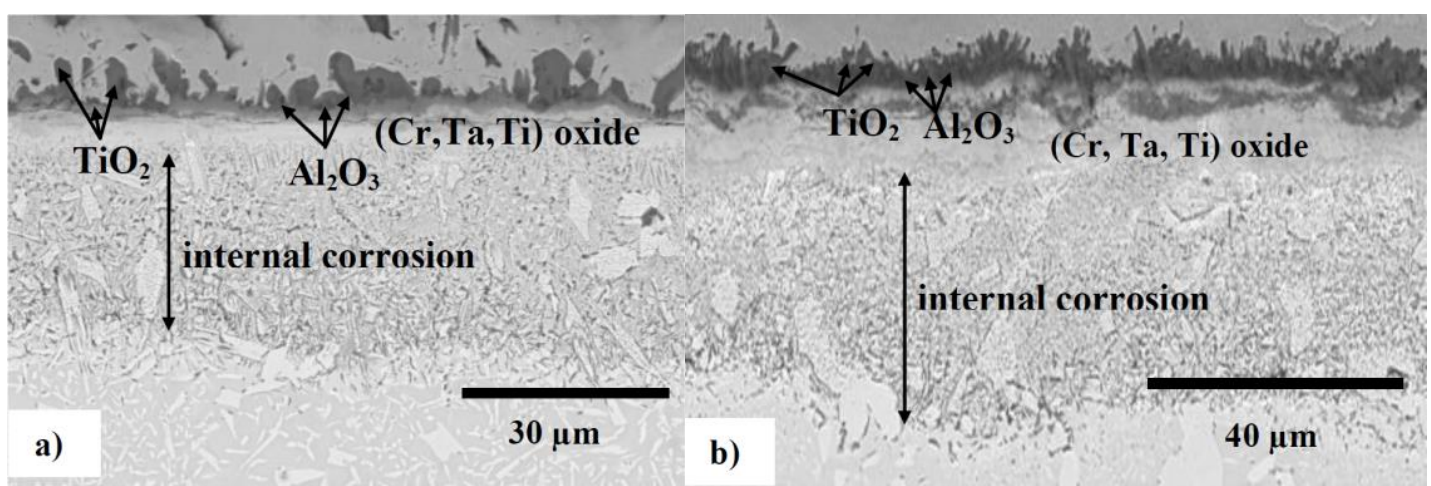

Figure 6. BSE images of a) Ta-Mo-Cr-Ti-Al and b) Ta-Mo-Cr-Ti-Al-1Si after $48 \mathrm{~h}$ of exposure in air at $1100{ }^{\circ} \mathrm{C}$. 


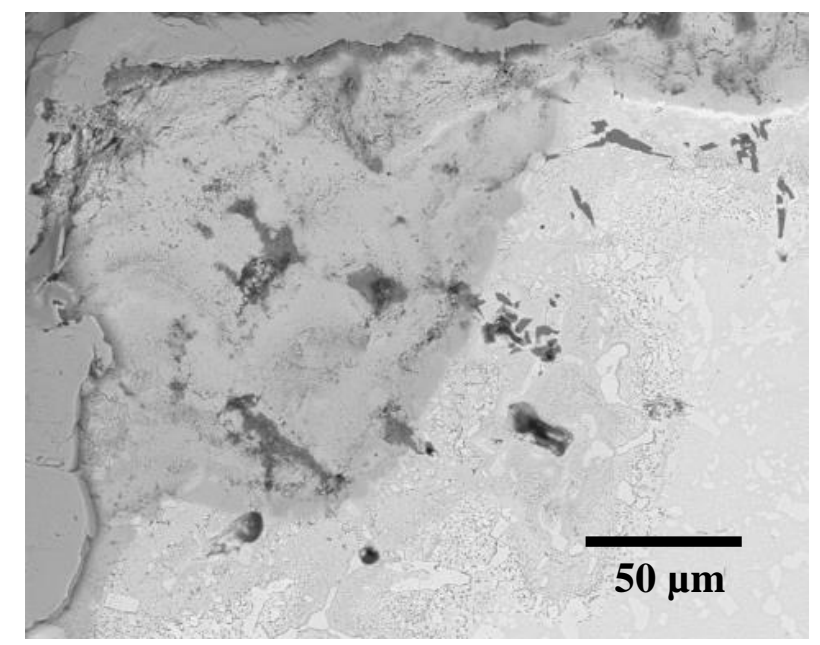

Figure 7. Example of a severely oxidized sample edge of Ta-Mo-Cr-Ti-Al-1Si after $48 \mathrm{~h}$ exposure in air at $1100^{\circ} \mathrm{C}$.

As mentioned above, both alloys show a pronounced zone of internal corrosion with large precipitates enriched in Ta and Cr. XRD measurements after $48 \mathrm{~h}$ of exposure to air at $1000^{\circ} \mathrm{C}$ revealed the formation of several nitrides, i.e. $\mathrm{TaN}, \mathrm{Ta}_{2} \mathrm{~N}$ and $\mathrm{Cr}_{2} \mathrm{~N}$ (see Fig. 5). Further EBSD measurements of the internal corrosion zones in both alloys documented even more corrosion products such as $\mathrm{CrN}, \mathrm{TiN}, \mathrm{Cr}_{2} \mathrm{O}_{3}$ and $\mathrm{Al}_{2} \mathrm{O}_{3}$. Figure 8 shows exemplarily results of the EBSD measurements of the internal corrosion zone in Ta-Mo-Cr-Ti-Al after $6 \mathrm{~h}$ of oxidation at $1000{ }^{\circ} \mathrm{C}$ in air. The results are in accordance with those obtained using XRD (see Fig.5). Interestingly, the appearance of the internal corrosion depends strongly on the size/shape and amount of the Laves phase (see Fig. 4). This means that the matrix near large Laves phase particles suffers from more severe inner corrosion attacks. The pronounced internal corrosion is already visible around the large Laves phase particles of Ta-Mo-Cr-Ti-Al-1Si after relatively short exposure time (6h) at $1000{ }^{\circ} \mathrm{C}$ (see Fig.9). Further, Fig. 9 clearly shows that the oxide scale formed on top of the Laves phase is much thinner and more protective than that formed on top of the matrix phase. EDX scans of oxide scales formed on top of Laves phase particles after $48 \mathrm{~h}$ of oxidation at $1000{ }^{\circ} \mathrm{C}$ (not shown here) further yield the formation of Ta- 
rich oxides beneath a thin outermost layer of chromia.
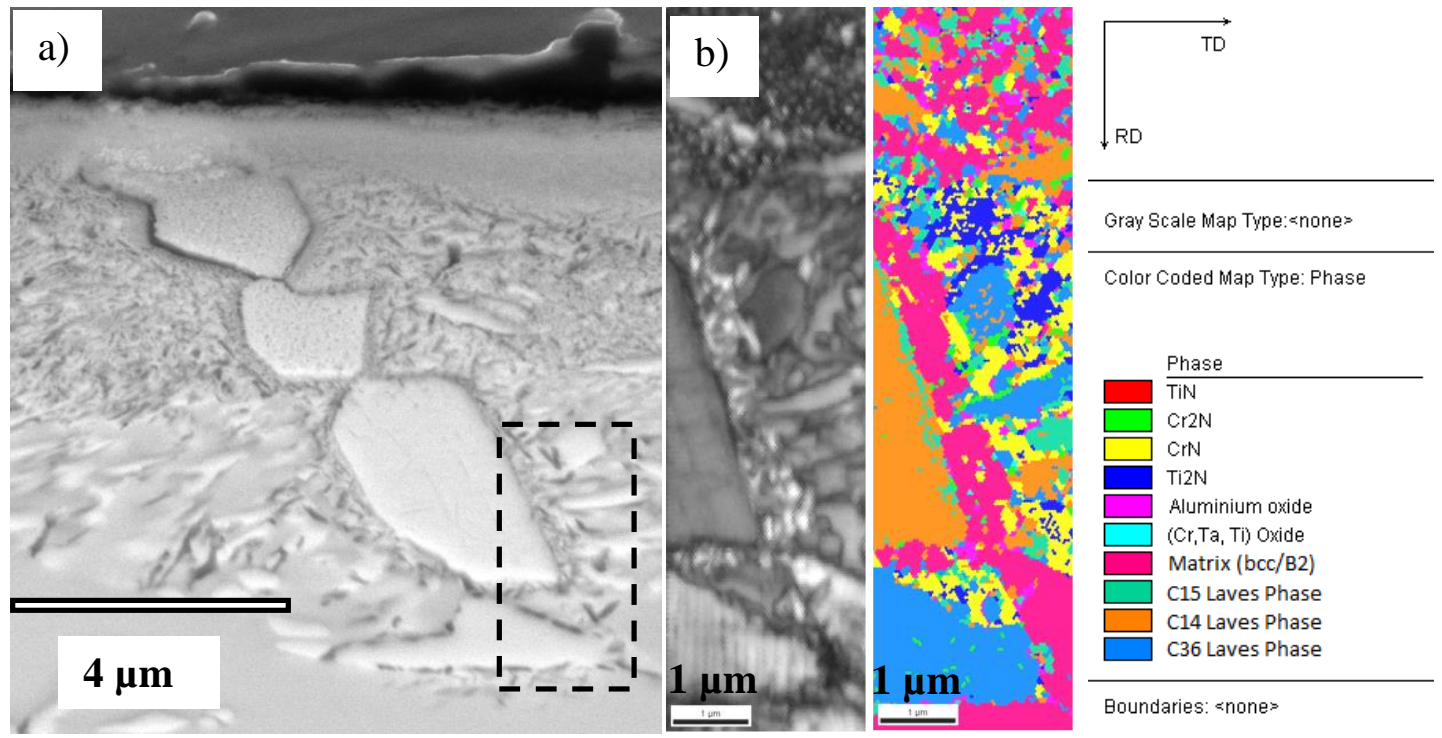

Figure 8. a) BSE cross section image and b) EBSD analysis of the marked zone in a) after $6 \mathrm{~h}$ of exposure of the alloy Ta-Mo-Cr-Ti-Al at $1000{ }^{\circ} \mathrm{C}$ in air.

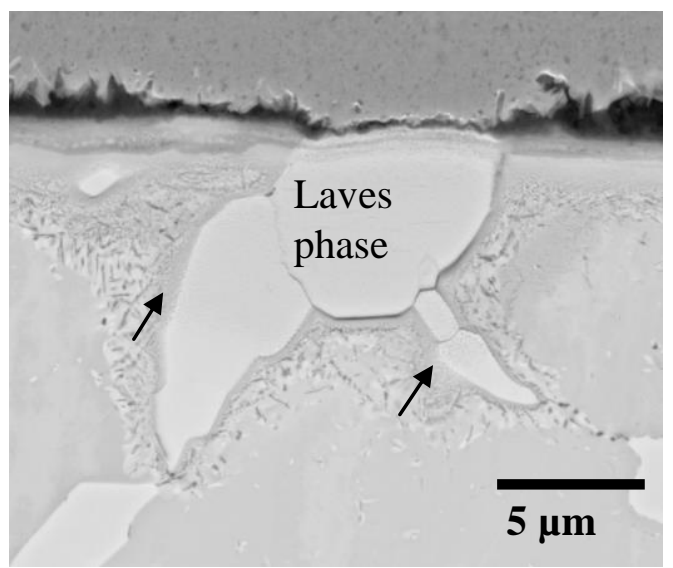

Figure 9. BSE micrographs of Ta-Mo-Cr-Ti-Al-1Si after $6 \mathrm{~h}$ of exposure in air at $1000{ }^{\circ} \mathrm{C}$. Massive internal corrosion along the phase boundaries of the big Laves phase is indicated by arrows.

\section{Discussion}

The thermogravimetric measurements conducted during oxidation of the alloy Ta-MoCr-Ti-Al-1Si show higher mass changes than those of the Si-free HEA at all temperatures. At $1100{ }^{\circ} \mathrm{C}$, Ta-Mo-Cr-Ti-Al-1Si exhibits increasing oxidation kinetics after $30 \mathrm{~h}$ of exposure similar to break-away oxidation, while parabolic oxidation was 
observed at lower temperatures. This strong increase in the oxidation kinetics can be attributed to the more pronounced internal corrosion in the vicinity of the Laves phase particles. Also, massive oxidation of one sample edge for Ta-Mo-Cr-Ti-Al-1Si after 48h of exposure at $1100^{\circ} \mathrm{C}$ in air occurred (see Fig. 7). The results of the TGA analyses correspond to those of the microstructural investigations: the oxide scales formed on the Si-containing alloys is slightly thicker compared to those formed on the Si-free alloy. Despite the high amount of highly reactive refractory elements, both alloys still exhibit good oxidation behaviour with small mass changes and low oxidation rates that are comparable with those of chromia and alumina forming alloys, respectively (see Fig. 10).

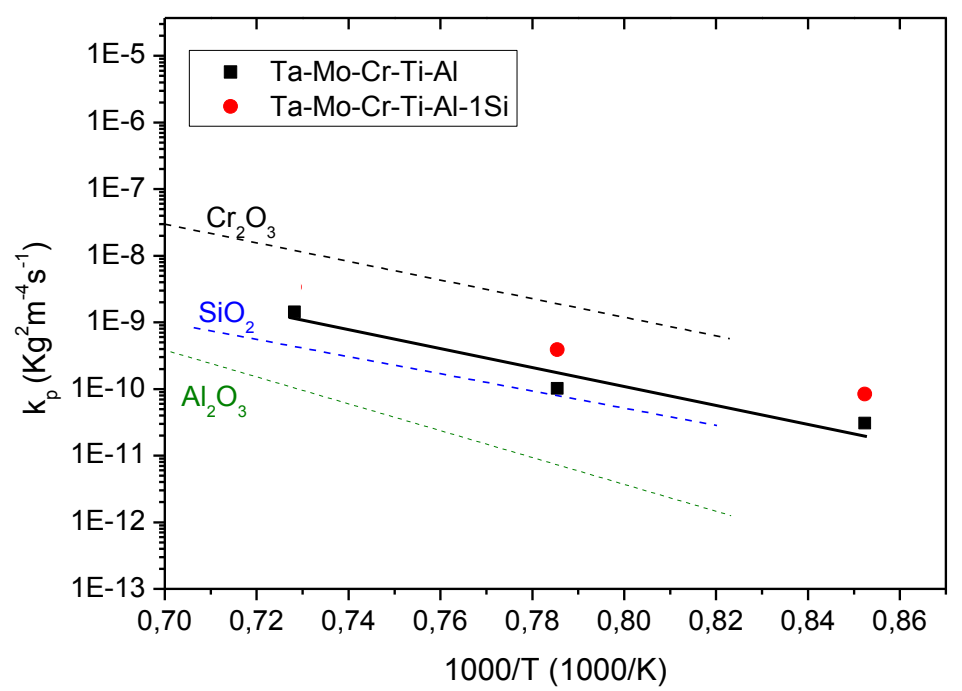

Figure 10. Overview of the parabolic rate constants for Ta-Mo-Cr-Ti-Al-(1Si) and Nibased alloys [21].

The high oxidation resistance between $900^{\circ} \mathrm{C}-1000^{\circ} \mathrm{C}$ of both alloys can be explained by the formation of alumina- and chromia-rich layers among the complex oxide scales. In general, the corrosion process of both alloys in the initial stage of oxidation can be rationalized by the interplay between the oxidation of the bcc/B2 matrix leading to the 
formation of a complex oxide scale including a protective alumina layer, the oxidation of the Laves phase resulting in the formation of a thin external chromia layer and the inner corrosion process causing the formation of nitrides $\mathrm{CrN}, \mathrm{Cr}_{2} \mathrm{~N}, \mathrm{TiN}$ and oxides, especially alumina (see Fig. 8). The severe formation of nitrides can apparently be attributed to the presence of the chromia scale. Chromia scales are generally permeable to nitrogen and the rapid formation of $\mathrm{Cr}_{2} \mathrm{~N}$, which occurs at a faster rate than $\mathrm{Cr}_{2} \mathrm{O}_{3}$, has been one of the major obstacles to the practical use of Cr-based alloys in nitrogen containing environments [22]. It can therefore be assumed that nitrogen diffuses through the chromia scales formed on the Laves phase particles as well as through the phase boundaries between the matrix and the Laves phase.

To assess the formation of possible corrosion products, the standard free energies of formation of relevant oxides and nitrides were calculated at $1000{ }^{\circ} \mathrm{C}$ using the commercial software FactSage. The corresponding values for the oxides and the nitrides are listed in tables 2 and 3, respectively. Obviously $\mathrm{TiO}_{2}$ and $\mathrm{Al}_{2} \mathrm{O}_{3}$ exhibit the lowest standard free energies. These compounds were found as external oxide scales as well as internally formed corrosion products. In terms of the thermodynamic stability, $\mathrm{TiO}_{2}$ and also $\mathrm{Al}_{2} \mathrm{O}_{3}$ are followed by $\mathrm{Ta}_{2} \mathrm{O}_{5}$ and $\mathrm{Cr}_{2} \mathrm{O}_{3}$ (see table 2). This may imply that below the chromia scale that forms on the Laves phase at the initial stage of oxidation the partial pressure of oxygen is still high enough for the formation of $\mathrm{Ta}_{2} \mathrm{O}_{5}$. Further, $\mathrm{Ta}_{2} \mathrm{O}_{5}$ may then react with chromia to form the $\mathrm{CrTaO}_{4}$ mixed oxide, which was observed in our study, according to the following reaction [23]:

$$
\mathrm{Cr}_{2} \mathrm{O}_{3}+\mathrm{Ta}_{2} \mathrm{O}_{5} \rightarrow 2 \mathrm{CrTaO}_{4}
$$

Moreover, since $\mathrm{Ta}_{2} \mathrm{O}_{5}, \mathrm{TiO}_{2}, \mathrm{CrTaO}_{4}$ and $\mathrm{SiO}_{2}$ all form oxides with the rutile crystal structure, it is possible that these oxides may react with each other leading to the 
formation of mixed rutile solid solutions after prolonged oxidation time. Tena et al. synthesized a rutile solid-solution $\mathrm{Cr}_{\mathrm{x}} \mathrm{Ti}_{1-2 \mathrm{x}} \mathrm{Ta}_{\mathrm{x}} \mathrm{O}_{2}(0<\mathrm{x}<0 \cdot 5)$ by firing mixtures of $\mathrm{Cr}_{2} \mathrm{O}_{3}, \mathrm{Ta}_{2} \mathrm{O}_{5}$ and $\mathrm{TiO}_{2}$ at $1300{ }^{\circ} \mathrm{C}$. They found that $\mathrm{CrTaO}_{4}$ formed as an intermediate rutile solid solution phase in samples synthesized by the oxide mixtures [24]. Also Joy et al. synthesized various mixed rutile solid solutions with the stoichiometry of $\mathrm{M}^{\prime} \mathrm{TiTaO}_{6}\left(\mathrm{M}^{\prime}=\mathrm{Al}, \mathrm{Cr}, \mathrm{Fe}\right)$ by mixing high purity of $\mathrm{Ta}_{2} \mathrm{O}_{5}, \mathrm{TiO}_{2}, \mathrm{Cr}_{2} \mathrm{O}_{3}$ and $\mathrm{Al}_{2} \mathrm{O}_{3}$ in stoichiometric proportions and subsequent heating between $900{ }^{\circ} \mathrm{C}$ and $1200^{\circ} \mathrm{C}$ [25]. To confirm whether the formation of such oxide solid solutions takes place in refractory HEAs presented in this paper, further investigations after both, shorter and longer exposure times are needed.

As mentioned above, the zones of internal corrosion were observed in both alloys at all temperatures, whereas more pronounced internal corrosion was identified in the Si-containing alloy. Obviously, the effect of internal corrosion appears to be the more important factor than scaling. In fact, the more pronounced internal corrosion in the Si-containing alloy seems to account for the increased mass change for the $\mathrm{Si}$ containing alloy. As mentioned above, especially the phase boundaries between the Laves phase particles and the matrix were susceptible to rapid and massive corrosion due to permeation of nitrogen through the thin chromia layer formed exclusively on the Laves phase. In addition, it is well-known that the diffusivity in phase- and grain boundaries is higher than in the bulk metal because the less closely packed atomic arrangement in the phase boundary offers faster diffusion paths. Laves phase, by contrast, exhibits complex and tightly-packed crystal structures with an overall packing density of 0.71 [26] which is even higher than the one in bcc/B2 (0.68) crystal structures. Thus, the Laves phases may exhibit lower oxygen/nitrogen permeability than the bcc/B2 matrix phase. For example, in the system Ti-Al-Cr, it was found that the $(\mathrm{Cr}$, 
$\mathrm{Al})_{2} \mathrm{Ti}$ Laves phase has a lower oxygen permeability than the hcp/bcc matrix phase and, thus, formed external alumina scales $[27,28]$. Based on these considerations, one can suppose the following relationship of oxygen and nitrogen diffusivity in both alloys Ta-

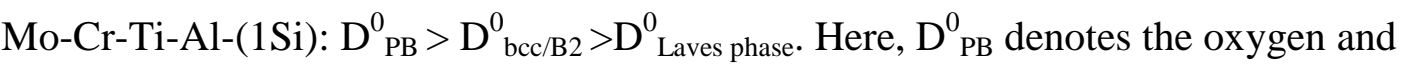
nitrogen diffusivity along phase boundaries. This assumption may explain the rapid corrosion of the phase boundaries between the matrix and the Laves phase (see Fig. 9). It should, however, be noted that the changes in the chemical compositions of the phases in the alloys may also affect the element activities influencing the diffusion processes in the alloy phases.

Laves phase remains, in contrary, largely unaffected by internal corrosion. As significantly more and larger particles of the Laves phase (and consequently more phase boundary area) are formed in the alloy Ta-Mo-Cr-Ti-Al-1Si (see Fig. 1), the internal corrosion attacks appear to be more severe than those in the Si-free alloy. It can, therefore, be concluded that the more pronounced internal corrosion, in addition to the slightly thicker oxide scales, can explain the higher mass change measured for the alloy Ta-Mo-Cr-Ti-Al-1Si during exposure in air at temperatures between $900^{\circ} \mathrm{C}$ and $1000^{\circ} \mathrm{C}$ compared to the Si-free alloy.

The reason why the silicon addition increases the volume fraction and the size of the Laves phase in Ta-Mo-Cr-Ti-Al-1Si is still unclear. Unfortunately, it was not possible for the present alloy system to determine the Si concentration in the different phases due to peak overlapping of Ta-M and Si-K peaks [29]. For binary $\mathrm{Cr}(\mathrm{Ta})-\mathrm{Cr}_{2} \mathrm{Ta}$ and $\mathrm{Cr}(\mathrm{Nb})-$ $\mathrm{Cr}_{2} \mathrm{Nb}$ alloys, however, it was found that with increasing Si content, Si partitions heavily into the Laves phase by occupying Cr sub-lattice sites. Therefore, the volume fraction of the Laves phase was observed to increase substantially in these alloy systems [12]. One may assume that in the alloys presented in this study, Si has a similar effect 
on the formation of the Laves phase. This phenomenon has to be confirmed in future studies by investigation of the microstructure of the alloy Ta-Mo-Cr-Ti-Al with different Si concentrations.

Further, for two phase $\mathrm{Cr}(\mathrm{Ta})-\mathrm{Cr}_{2} \mathrm{Ta}$ alloys it has been reported that the $\mathrm{Cr}_{2} \mathrm{Ta}$ Laves phase acts as a sink for nitrogen and effectively getters a flux of nitrogen that passes through the scale [30]. If the scale, however, becomes highly permeable to nitrogen and a strong inward diffusion of nitrogen through grain/phase boundaries takes place massive nitridation of the matrix phase between the Laves phase particles may result [31]. The EBSD measurements ( see Fig. 8) on the alloy Ta-Mo-Cr-Ti-Al after $6 \mathrm{~h}$ of exposure to $1000{ }^{\circ} \mathrm{C}$ confirm this hypothesis by exhibiting preferential formation of metastable $\mathrm{CrN}$ (see table 3). Apparently, the thermodynamic equilibrium is not reached after $6 \mathrm{~h}$ of oxidation. However, after $48 \mathrm{~h}$ of exposure, the stable modification of the $\mathrm{Cr}-$ nitride, $\mathrm{Cr}_{2} \mathrm{~N}$, was detected (see Fig. 5).

Table 2. Standard free energy of formation of oxides at $1000{ }^{\circ} \mathrm{C}$.

\begin{tabular}{|l|l|l|l|l|l|}
\hline Oxide & $\mathrm{Cr}_{2} \mathrm{O}_{3}$ & $\mathrm{Ta}_{2} \mathrm{O}_{5}$ & $\mathrm{TiO}_{2}$ & $\mathrm{Al}_{2} \mathrm{O}_{3}$ & $\mathrm{MoO}_{3}$ \\
\hline$\Delta \mathrm{G}^{0}\left[\mathrm{~kJ} / \mathrm{mole}_{2}\right]$ & -538 & -598 & -713 & -853 & -293 \\
\hline
\end{tabular}

Table 3. Standard free energy of formation of nitrides at $1000{ }^{\circ} \mathrm{C}$.

\begin{tabular}{|l|l|l|l|l|l|l|l|}
\hline Nitrides & $\mathrm{Cr}_{2} \mathrm{~N}$ & $\mathrm{CrN}$ & $\mathrm{Ti}_{2} \mathrm{~N}$ & $\mathrm{TiN}$ & $\mathrm{TaN}$ & $\mathrm{Ta}_{2} \mathrm{~N}$ & $\mathrm{AlN}$ \\
\hline$\Delta \mathrm{G}^{0}\left[\mathrm{~kJ} / \mathrm{mole}_{2}\right]$ & -64 & -41 & -499 & -435 & -302 & -323 & -367 \\
\hline
\end{tabular}


With regard to the high temperature oxidation resistance, this study shows the high potential of refractory HEAs. Although these results suggest that the addition of Si had no direct beneficial effect on the oxidation resistance, the effect of Si might be rather complex and should be investigated further. Therefore, the following investigations will be made and will be published in our future works:

1) The effect of nitridation on the high temperature corrosion is rather strong and should be suppressed by using Ar-20 vol. $\% \mathrm{O}_{2}$ atmosphere for the future oxidation experiments. In addition, several discontinuous experiments with short exposure times will be made to investigate the transient oxidation behavior.

2) The volume fraction and size of the Laves phase will be increased by additional heat treatment and the effect on the high temperature oxidation behavior in Ar$20 \mathrm{O}_{2}$ atmosphere will be investigated.

3) Besides, the volume fraction of the Laves phase will be decreased by variation of the $\mathrm{Cr}$ and Ta concentrations, too. Thereby, the effect of the chemical composition and the microstructure on the high temperature oxidation behavior under Ar-20 vol. $\% \mathrm{O}_{2}$ atmosphere should be investigated.

\section{Summary}

In this study the effect of 1 at. $\% \mathrm{Si}$ addition on the microstructure and high temperature oxidation resistance of the novel refractory alloy Ta-Mo-Cr-Ti-Al was investigated. The following findings can be summarized:

1.) Both alloys consist of a bcc/B2 matrix with $\mathrm{Cr}_{2} \mathrm{Ta}$ Laves phase particles of the three modifications, i.e. cubic $\mathrm{C} 15$, hexagonal $\mathrm{C} 14$ and $\mathrm{C} 36$, at the grain 
boundaries and inside the grains. The addition of Si clearly increases the volume fraction and size of the $\mathrm{Cr}_{2} \mathrm{Ta}$ Laves phase particles.

2.) The oxidation resistance of both alloys between $900^{\circ} \mathrm{C}$ and $1100{ }^{\circ} \mathrm{C}$ in air is on the level of chromia forming alloys due to the formation of protective chromia-rich and alumina-rich scales. In addition, $\mathrm{TiO}_{2}, \mathrm{Ta}_{2} \mathrm{O}_{5}$ or $\mathrm{CrTaO}_{4}$ mixed oxide layers were found. The slightly higher oxidation rates were observed for the alloy Ta-Mo-Cr-Ti-Al-1Si as compared to the Si-free HEA. This is explained by the marginally thicker oxide scales and notably more pronounced internal corrosion attacks identified for the Si-containing alloy.

3.) The phase boundaries between the Laves phase and the bcc/B2 matrix serve as preferred diffusion paths for the oxygen and nitrogen ingress. The internal corrosion process along the phase boundaries is more pronounced along the bigger Laves phase particles of Ta-Mo-Cr-Ti-Al-1Si and is probably the main reason for the deleterious effect of 1at.\% Si addition on the high temperature oxidation resistance of the alloy Ta-Mo-Cr-Ti-Al-1Si.

\section{Acknowledgment}

The financial support by Deutsche Forschungsgemeinschaft (DFG) is gratefully acknowledged.

\section{References}

[1] Yeh J, Chen LY, Lin SJ, et al. High entropy alloys - A new era of exploitation. Mater Sci Forum. 2007;560:1-9.

[2] Senkov ON, Woodward C, Miracle DB. Microstructure and properties of aluminumcontaining refractory high entropy alloys. JOM-J Min Met Mat S. 2014; 66:2030-2042. 
[3] Senkov ON, Senkova SV, Dimiduk DM, et al. Oxidation behavior of a refractory NbCrMo0.5Ta0.5TiZr alloy. J Mater Sci. 2012;47:6522-6534.

[4] Gao M, Yeh JW, Liaw PK, et al. High entropy alloys-fundamentals and applications. Springer International Publishing Switzerland, 2016.

[5] Miracle DB, Senkov ON. A critical review of high entropy alloys and related concepts. Acta Mater. 2017;122:448-511.

[6] Senkov ON, Senkova SV, Woodward C, et al. Low-density, refractory multiprincipal element alloys of the $\mathrm{Cr}-\mathrm{Nb}-\mathrm{Ti}-\mathrm{V}-\mathrm{Zr}$ system: Microstructure and phase analysis. Acta Mater. 2013;61:1545-1557.

[7] Senkov ON, Woodward C, Miracle DB. Microstructure and properties of aluminumcontaining refractory high entropy alloys. JOM-J Min Met Mat S.2014;66:20302042.

[8] Senkov ON, Isheim D, Seidman DN, et al. Development of a refractory high entropy superalloy. Entropy. 2016;16:1-13.

[9] Chen H, Kauffman A, Gorr B, et al. Microstructure and mechanical properties at elevated temperatures of a new Al-containing refractory high entropy alloy $\mathrm{Nb}$ Mo-Cr-Ti-Al. J Alloy Compd. 2015;661:206-215.

[10] Senkov ON, Senkova SV, Dimiduk DM, et al. Oxidation behavior of a refractory NbCrMo0.5Ta0.5TiZr alloy. J Mater Sci. 2012;47:6522-6534.

[11] Gorr B, Mueller F, Christ H-J, et al. High temperature oxidation behavior of an equimolar refractory metal-based alloy 20Nb20Mo20Cr20Ti20Al with and without Si addition, J Alloy Compd. 2016;688:468-477.

[12] Bhowmik A, Pang HT, Edmonds IM, et al. Effect of silicon additions on the high temperature oxidation behaviour of $\mathrm{Cr}-\mathrm{Cr}_{2} \mathrm{Ta}$ alloys. Intermetallics. 2013;32:373-383.

[13] Scott FH, Gabriel GJ, Wei FI, et al. The development of silicon-containing oxides during the oxidation of iron-chromium-base alloys. Mater Corros. 1987;38:521531.

[14] Evans HE, Hilton DA, Holm RA, et al. Influence of silicon additions on the oxidation resistance of a stainless steel. Oxid Met. 1983;19:1-12.

[15] Jones DE and Stringer J. The effect of small amounts of silicon on the oxidation of high-purity Co-25 wt. \% Cr at elevated temperatures. Oxid Met.1975;9:409-413. 
[16] Heilmaier M, Krüger M, Saage H, et al. Metallic materials for structural applications beyond nickel-based superalloys, JOM-J Min Met Mat S. 2009;61:61-67.

[17] Li B and Gleeson B. Effects of silicon on the oxidation behavior of Ni-base chromia-forming alloys. Oxid Met. 2006;65:101-122.

[18] Radavich JF. Effect of silicon on high temperature oxidation of stainless steels. Corrosion. 1959;15:613-617.

[19] Durham R, Gleeson B, Young DJ. Silicon contamination effects in the oxidation of carbide-containing cobalt-chromium alloys, Mater Corros. 1998;49:855-863.

[20] Wang S, Wu Y, Gesmundo F, et al. The effect of Si additions on the hightemperature oxidation of a ternary $\mathrm{Ni}-10 \mathrm{Cr}-4 \mathrm{Al}$ alloy in 1 atm $\mathrm{O}_{2}$ at $900^{\circ} \mathrm{C}-$ $1000{ }^{\circ}$ C. Oxid Met. 2008;69:299-315.

[21] Cahn RW, Haasen P, Kramer EJ. Materials science and technology; materials corrosion and environmental degradation, Part I and II. Weinheim: Wiley-VCH; 2000.

[22] Klopp WD. Recent Developments in Chromium and Chromium Alloys. NASA Technical Memorandum (US);1969. (NASA TM X-1867).

[23] Massard P, Bernier JC, Michel A. Effet Jahn-Teller dans le système $\mathrm{Ta}_{2} \mathrm{CrO}_{6^{-}}$ $\mathrm{TaCrO}_{4}$. J Solid State Chem. 1972;4:269-274.

[24] Tena MA, Llusar M, Badenes JA, et al. Influence of precursors on formation of $\mathrm{TiO}_{2}-\mathrm{CrTaO}_{4}$ rutile solid solutions. Brit Ceram T. 2000;99:219-224.

[25] Joy JE, Nag A, Gopalakrishnan J, et al. FeTiTaO6: A lead-free relaxor ferroelectric based on the rutile structure. Adv Mater. 2008;20:1348-1352.

[26] Murray MJ, Sanders JV. Close-packed structures of spheres of two different sizes II. The packing density of likely arrangements. Philosophical Magazine A. 1980;42:721-740.

[27] Brady MP, Smialek JL, Smith J, et al. The role of Cr in promoting protective alumina scale formation by y-based Ti-Al-Cr alloys-Part I. Acta Mater.1997;45:2357-2369.

[28] Brady MP, Smialek JL, Smith J, et al. The role of $\mathrm{Cr}$ in promoting protective alumina scale formation by y-based Ti-Al-Cr alloys-Part II. Acta Mater.1997;45:2371-2382.

[29] Statham PJ. Limitations to accuracy in extracting characteristic line intensities from X-ray spectra, J Res Natl Inst Stand Technol.2002;107:531-546. 
[30] Brady MP, Zhu JH, Liu CT, et al. Oxidation resistance and mechanical properties of Laves phase reinforced Cr in-situ composites. Intermetallics. 2000;8:11191129.

[31] Anton DL, Shah DM, Duhl DN, et al. Selecting high-temperature structural intermetallic compounds: The engineering approach. JOM-J Min Met Mat S. $1989 ; 41: 12-17$. 